\title{
NICKEL-COBALT OXIDE THIN-FILMS ANODES FOR LITHIUM-ION BATTERIES
}

\author{
${ }^{1}$ llya MITROFANOV, 'Denis NAZAROV, ${ }^{1}$ Yury KOSHTYAL, ${ }^{1}$ llya EZHOV, ${ }^{1}$ Pavel FEDOROV, \\ ${ }^{2}$ Aleksander RUMYANTSEV, ${ }^{1}$ Anatoliy POPOVICH, ${ }^{1}$ Maxim MAXIMOV* \\ ${ }^{1}$ Peter the Great Saint-Petersburg Polytechnic University, Saint-Petersburg, Russia, maximspbstu@mail.ru \\ ${ }^{2}$ loffe Institute, Saint-Petersburg, Russia
}

https://doi.org/10.37904/nanocon.2020.3714

\begin{abstract}
Thin-film transition metal oxides can be applied as transparent conductive coatings, photocatalysts, thermoelectric generators, and battery electrodes. In power sources application binary transition metal oxides are attractive due to high theoretical capacities. Among them nickel-cobalt oxides possess the highest $\left(\mathrm{NiCoO}_{2}, 717 \mathrm{mAh} / \mathrm{g}\right.$ or $\left.471.4 \mu \mathrm{Ah} \mathrm{cm}^{-2} \mu \mathrm{m}^{-1}\right)$. This work is devoted to Atomic layer deposition (ALD) of thinfilms of nickel-cobalt oxides and evaluating their performance as negative electrodes for solid-state lithium-ion batteries. Ni-Co-O thin films were synthesized with different NiO/CoO ALD cycles ratio (5/1, 3/1, and 1/1) using nickelocene, cobaltocene and oxygen plasma. Both $\mathrm{NiO}$ and $\mathrm{CoO}$ crystal phases were observed in deposited films. The content of chemical elements $(\mathrm{C}, \mathrm{O}, \mathrm{Ni}$ and $\mathrm{Co})$ in the film's depth are uniform, except for sample $5 / 1$. The electrochemical performance of synthesized thin films was studied by cyclic voltammetry and galvanostatic cycling. It was found that with an increase of the nickel content in the coatings, the electrode's specific capacity is increasing. The highest capacity at high discharge currents $(35 \mathrm{C})$ is observed for the sample obtained with $\mathrm{NiO} / \mathrm{CoO}-5 / 1$ ratio $\left(660 \mu \mathrm{A} \cdot \mathrm{h} \cdot \mu \mathrm{m}^{-1} \cdot \mathrm{cm}^{-2}\right)$
\end{abstract}

Keywords: Atomic layer deposition, Nickel-cobalt oxide, lithium-ion batteries, solid-state lithium-ion batteries

\section{INTRODUCTION}

Solid-state thin-film lithium-ion batteries (SSLIBs) can be applied to power various miniature devices [1]: medical implants [2], "smart" bank cards, RFID tags, etc. The increase of operating time (that is usability) requires power sources with higher energy density.

SSLIBs can be manufactured using chemical vapor deposition, pulsed laser deposition, dip coating, and atomic layer deposition [3-5] (ALD). ALD is a promising technology that allows the deposition of films of various materials with high thickness accuracy on flat and three-dimensional substrates.

Nickel oxide and cobalt oxide are promising materials for SSLIBs [6-8] and have high theoretical capacities (715-746 mAh/g [9], 425-480 $\left.\mu \mathrm{Ah} \cdot \mu \mathrm{m}^{-1} \cdot \mathrm{cm}^{-2}\right)$. The chemical composition of the active material can affect the electrochemical activity and service life of the electrodes. In this regard, we studied the effect of the chemical composition of films of mixed nickel and cobalt oxide obtained by the ALD method using the supercycle approach [3].

\section{MATERIALS AND METHODS}

Silicon (surface orientation (100), $40 \times 40 \mathrm{~mm}^{2}$, Telecom-STV Co., Ltd., Zelenograd, Russia) and stainlesssteel (316SS, 16 mm diameter plates, Tob New Energy Technology Co., Ltd., Xiamen, China) were used as substrates. The substrates were cleaned in an ultrasonic bath in acetone and deionized water for 10 and 5 min, respectively. The native oxide layer was removed by immersion of silicon wafer in $10 \% \mathrm{HF}$ solution for 5 min. Then, to remove organic contaminants and produce a hydroxylic surface, silicon substrates were cleaned 
using piranha solution $\left(\mathrm{H}_{2} \mathrm{SO}_{4} / \mathrm{H}_{2} \mathrm{O}_{2}\right.$, volume ratio $\left.7: 3\right)$ for $20 \mathrm{~min}$, rinsed in deionized water, and dried under an argon atmosphere [10].

ALD processes of nickel-cobalt oxide (NCO), nickel oxide (NO), and cobalt oxide (CO) were performed by a commercial R-150 setup (Picosun Oy, Espoo, Finland) at a temperature $300^{\circ} \mathrm{C}$ and a reactor base pressure of 8-12 hPa. Bis(cyclopentadienyl) nickel(II) and Bis(cyclopentadienyl) cobalt(II) (Ni(Cp)2, Co(Cp)2; 99\%, Dalchem, Nizhny Novgorod, Russia) were used as the nickel- and cobalt-containing precursors. $\mathrm{Co}(\mathrm{Cp})_{2}$ and $\mathrm{Ni}(\mathrm{Cp})_{2}$ were kept in stainless-steel bottles (PicohotTM 200, Picosun Oy) and heated to 160 and $110{ }^{\circ} \mathrm{C}$, respectively. Pulse times and purge times were $1 \mathrm{~s}$ and 10 s, respectively, for both $\mathrm{Co}(\mathrm{Cp})_{2}$ and $\mathrm{Ni}(\mathrm{Cp})_{2}$. Remote oxygen plasma was used as a counter-reagent $\left(\mathrm{pO}_{2}\right)$. The plasma power was $3 \mathrm{~kW}$, with a frequency range of 1.9-3.2 MHz. The total oxygen plasma pulse time was $19.5 \mathrm{~s}$ (Ar purge during $0.5 \mathrm{~s}$ with flow rate $40 \mathrm{sccm}$; $\mathrm{Ar}$ and $\mathrm{O} 2$ plasma purge during $14 \mathrm{~s}$ with flow rate $90 \mathrm{sccm}$; Ar purge during $5 \mathrm{~s}$ with flow rate $40 \mathrm{sccm}$ ). Deposition conditions were based on our previous studies devoted to obtaining cobalt and nickel oxide [11,12]. Synthesized films were denoted as NCO 1/1, 3/1,5/1, which correspond to NiO/CoO pulse ration in supercycle $\left(\left[\mathrm{n} \cdot(\mathrm{Ni}-\mathrm{pO} 2)+\mathrm{m} \cdot\left(\mathrm{Co}-\mathrm{pO}_{2}\right)\right]\right)$.

The thickness of the films was determined using an Ellips-1891 SAG ellipsometer (CNT, Novosibirsk, Russia) in a wavelength range from 370 to $1000 \mathrm{~nm}$ (at an incidence angle of $70^{\circ}$ ) and the Spectr software package (1.10, CNT, Novosibirsk, Russia). The growth per cycle (GPC) and growth per supercycle (GPSC) were calculated by dividing film thickness by the number of cycles/supercycles.

X-ray diffraction (XRD) studies were performed by Bruker D8 DISCOVER (Cu-Ka, Billerica, MA, USA) diffractometer. Surface-sensitive grazing incidence XRD (GIXRD) mode was used for XRD measurements using $2 \theta$ range of $15-65^{\circ}$ with a step of $0.1^{\circ}$ and an exposure of $1 \mathrm{~s}$ at each step.

Escalab 250Xi spectrometer (Thermo Fisher Scientific, Waltham, MA, USA) was used to obtain X-ray photoelectron spectra (XPS). The samples were etched by $\mathrm{Ar}+$ ions with $3 \mathrm{keV}$ energy for 30 and $90 \mathrm{~s}$ for depth profiling studies. The samples were excited by Al-Ka $(1486.7 \mathrm{eV}) \mathrm{X}$-rays at a pressure of $7 \times 10^{-8} \mathrm{~Pa}$.

The thin films deposited on stainless-steel plates were used for electrochemical studies in CR2032 coin cells. Lithium foil, polyolefin porous film 2325 (Celgard, Charlotte, NC, USA), and TC-E918 (Tinci, Guangzhou, China) solution were used as the counter electrode, separator, and electrolyte, respectively. Coin cells were assembled in an argon atmosphere using OMNI-LAB glove box (VAC). Cyclic voltammetry (CV) was performed using PGSTAT302N+ potentiostat (Autolab, Utrecht, the Netherlands) in the range of $0.01-3 \mathrm{~V}$ with a scan rate of $0.5 \mathrm{mV} / \mathrm{s}$. Cyclic charge/discharge was performed using the battery testing system CT-3008W$5 \mathrm{~V} 10 \mathrm{~mA}$ (Neware, Shenzhen, China) at room temperature in the potential range of $0.01-3 \mathrm{~V}$, current range $20-1600 \mu \mathrm{A}$.

\section{RESULTS AND DISCUSSION}

\subsection{Film characterization}

The deposition of films was effectuated with the use of the supercycle approach. To deposit NCO 1/1, NCO $3 / 1$ and NCO 5/1, the 900 (1800), 470 (1880) and 310 (1860) supercycles (cycles) of synthesis were conducted. According to spectral ellipsometry measurements, the thicknesses of the NCO 1/1, NCO 3/1 and, NCO 5/1 films were $45.9 \mathrm{~nm}, 44.2 \mathrm{~nm}$ and, $36.3 \mathrm{~nm}$, respectively.

The GPC determined from spectral ellipsometry analysis of $\mathrm{NiO}$ and $\mathrm{CoO}$ films are $0.12 \pm 0.01 \AA /$ cycle [11] and $0.25 \pm 0.02 \AA[12]$, respectively. Thus, the decrease of GPC of mixed oxide with number of $\mathrm{NiO}$ cycles increment in supercycle is expected (Figure 1). The observed augmentation of GPSC is also evident since the number of deposition cycles in one supercycle is augmented. For most samples, a good agreement between calculated values of GPC of mixed oxide films (basing on GPC of monoxides) and derived from 
ellipsometry measurements of deposited mixed oxide films is observed (0.01-0.03 $\AA$ /cycle difference). The slight increase of GPC and GPSC of deposited mixed oxide films may occur due to their lower density.
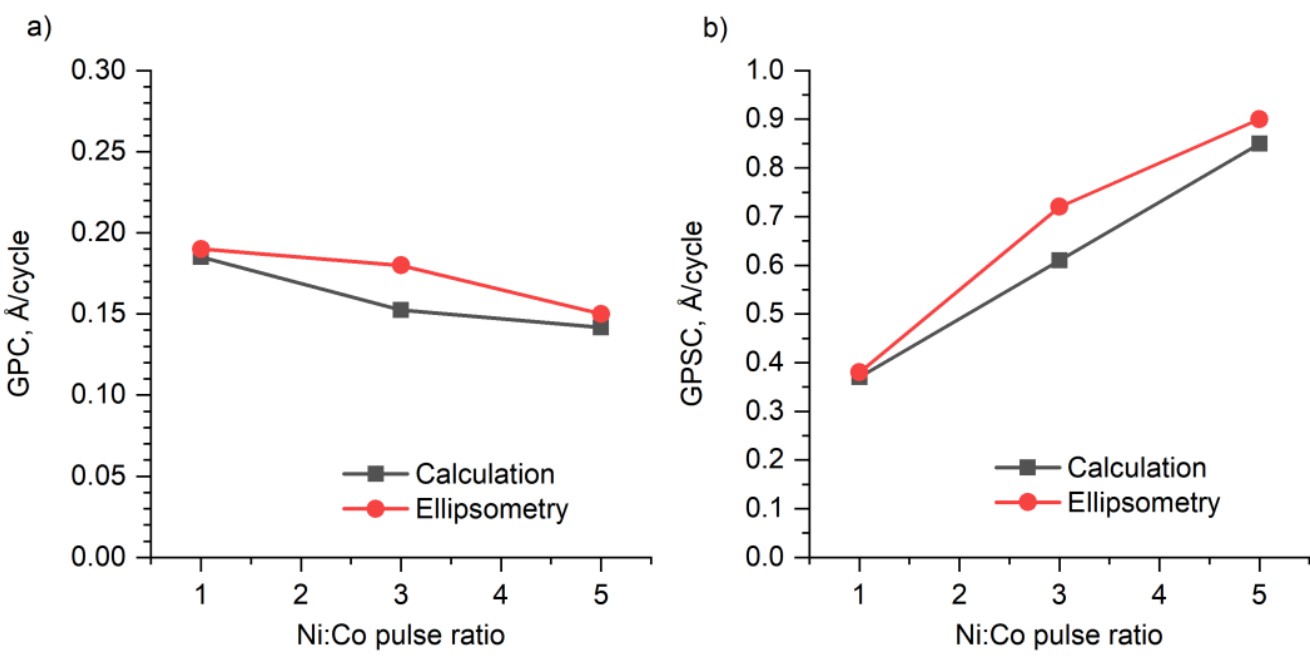

Figure 1 Growth per cycle(a) and growth per supercycle (b) of NCO thin films

Several reflexes were observed on the XRD patterns of deposited films. The peaks situated in $55,56.5$, and $62^{\circ}$ are appeared due to defects of silicon substrates. The rest reflexes presented at $37,43,63^{\circ}$ are associated with crystal phases of nickel oxide (PDF 01-071-1179) and cobalt oxide (PDF 01-061-1227). Thus, the deposition conducted at $300^{\circ} \mathrm{C}$ resulted in the formation of crystal phases of $\mathrm{NiO}$ and $\mathrm{CoO}$.
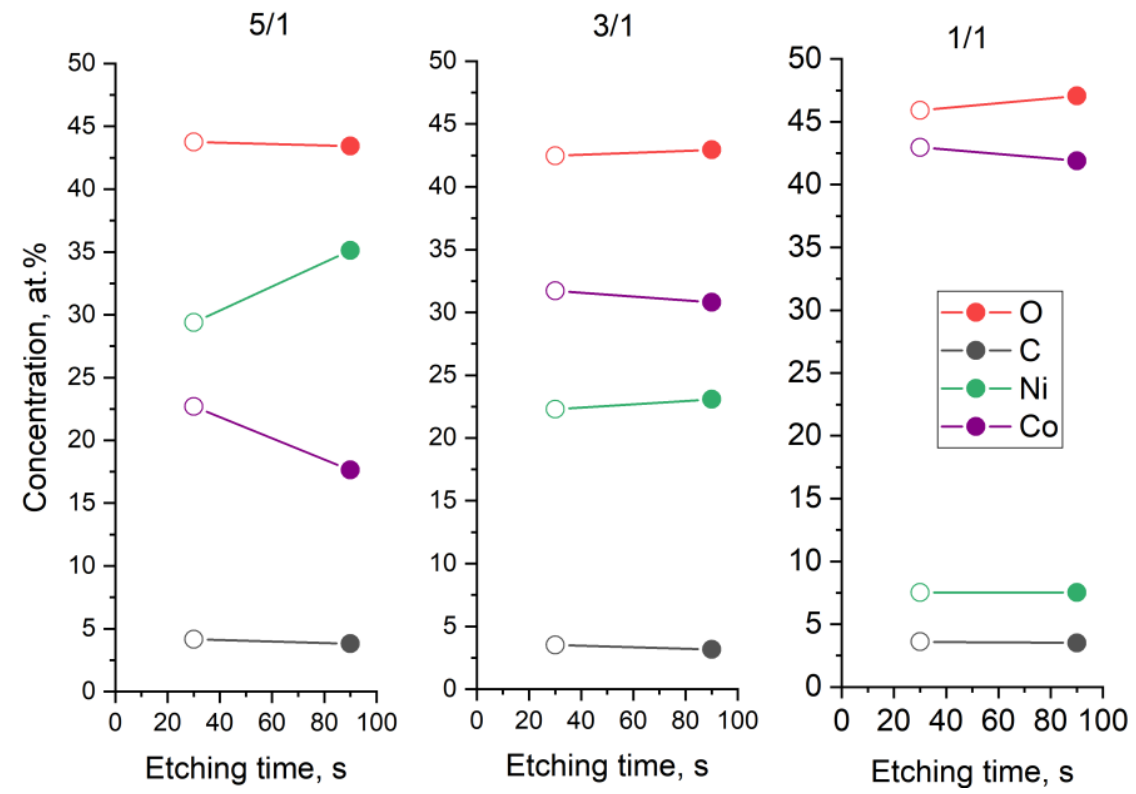

Figure 2 XPS profiling of NCO films

The Chemical composition of the films was estimated using XPS after etching during 30 and $90 \mathrm{~s}\left(\mathrm{Ar}^{+}, 3 \mathrm{keV}\right)$ (Figure 2). The first etching allows the elimination of hydrocarbon residues adsorbed from the atmosphere. According to the results of the experiments, the etching rate of nickel-cobalt oxide films in the chosen conditions is $0.77 \AA / s$. Therefore, XPS measurements performed after 90 s of etching shows the composition of the film at a depth of $5-10 \mathrm{~nm}$. For all samples and etching time, the concentration of carbon is stable, doesn't exceed 4.2 At.\%, and might be caused by residues of $\mathrm{Ni}$ and Co precursor ligands. The concentration of transition 
metal (Ni, Co) augments with an increment of cycles effectuated for transition metal oxide deposition. The content of all elements in the film's depth is uniform, except for sample 5/1, where an increase in the proportion of nickel in the depth of the film is observed in proportion to a decrease in the proportion of cobalt (about $5 \%$ ). An oxygen concentration varies from 42.5 to 47 at.\%. The sum of transition metal concentration varies from 49 to 54 at.\%. The ratio of concentrations - transition metals/oxygen is higher than 1 . Thus part of metals may retain metal-carbon bonds or present in zero oxidation state.

\subsection{Electrochemical analysis}

With a potential decrease from 3.0 to $0 \mathrm{~V}$, an intense increase of current observed in the $0.2-0.8 \mathrm{~V}$ area is observed. It can be related to the reduction of electrolyte components on the surface of materials [11]. The form of the observed current maximum is asymmetrical, and it may characterize at least to reduction reaction (with the participation of nickel or cobalt atoms). The subsequent increase of potential is accompanied by the increase of current in the $1.5-2.5 \mathrm{~V}$ region. A shoulder at $1.62 \mathrm{~V}$ is observed, and it is related to SEI electrochemical activity. The position of the main maximum shifts from 2.1 to 2.21 with an increment of nickel content. Thus, it can be concluded that maximum in the 2.1-2.21 region is related to oxidation reaction with transition metals $\left(2.0 \mathrm{~V} \mathrm{CoO}\right.$ [13], 2.05 $\mathrm{V} \mathrm{Co}_{3} \mathrm{O}_{4} \cdot[13], 2.22 \mathrm{~V} \mathrm{NiO}$ [11]). On the $\mathrm{CV}$ cathode curves of the $2^{\text {nd }}-9^{\text {th }}$ cycle, asymmetrical peak (peaks) are observed in the $0.6-1.5 \mathrm{~V}$ region while the increase of current observed during the first cycle is no longer presented. The noted current increase may be related to the reaction of transition metal oxide with lithium [14]. On the anode curves, the peaks observed on the first cycle are remained at following cycles, but their positions are slightly shifted to higher potentials.

After CV, the samples charged-discharged at different currents (20-1600 $\mu \mathrm{A}$ correspond to 25-42C). The specific discharge capacity of NCO 1/1, NCO 3/1, and NCO 5/1 at highest discharge currents were equal 470 $\mu \mathrm{A} \mathrm{h} \mu \mathrm{m}^{-1} \mathrm{~cm}^{-2}$ (25.5C), $650 \mu \mathrm{A} \mathrm{h} \mu \mathrm{m}^{-1} \mathrm{~cm}^{-2}$ (29C), and $660 \mu \mathrm{A} \mathrm{h} \mu \mathrm{m}^{-1} \mathrm{~cm}^{-2}$ (35C). Therefore, the increase in nickel content provides better $\mathrm{C}$-rate performance due to possible solid electrolyte interphase (SEI) contribution which increases with nickel content. The theoretical capacities of nickel oxide and cobalt oxide are approximately equal $(718$ and $715 \mathrm{mAh} / \mathrm{g})$. Probably, NiO better promotes the decomposition of the electrolyte to form an SEI film. When studying the electrochemical characteristics of thin films, SEI makes a significant contribution to the measured capacitance. Accordingly, higher NiO (SEI) content promotes higher capacity values.

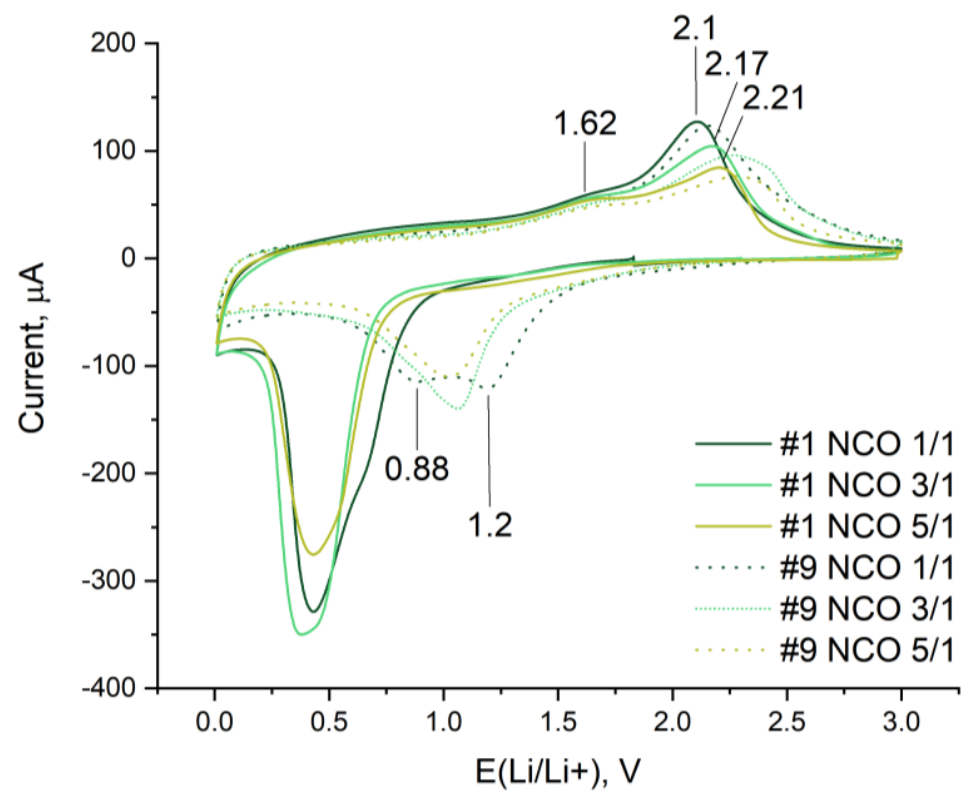

Figure 3 Cyclic voltamperograms of NCO thin films obtained at first and ninth cycle 


\section{CONCLUSION}

Thin films (36-46 nm) of mixed nickel and cobalt oxides with a different ration of Ni/Co were deposited on silicon and stainless steel substrates using the ALD method. The growth per supercycle of the mixed oxide film was close to the linear combination of $\mathrm{NiO}$ and $\mathrm{CoO}$ cycles deposition. Both $\mathrm{NiO}$ and $\mathrm{CoO}$ crystal phases were observed in deposited films.

The increase in the number of transition metal ( $\mathrm{Ni}, \mathrm{Co})$ oxide deposition cycles led to increased transition metal content in the film. Carbon (less than 4.2 at.\%) was observed on the external surface and in the films' depth. An atomic concentration of transition metal exceeds oxygen concentration; thus, part of transition metal may be presented in a lower oxidation state.

According to electrochemical investigations, the specific capacity and rate performance increase with nickel content, due to possible solid electrolyte interphase (SEI) contribution which increases with to nickel content. The highest capacity at high discharge currents (35C) is observed for the sample obtained with $\mathrm{NiO} / \mathrm{CoO}-5 / 1$ ratio $\left(660 \mu \mathrm{A} \cdot \mathrm{h} \cdot \mu \mathrm{m}^{-1} \cdot \mathrm{cm}^{-2}\right)$.

\section{ACKNOWLEDGEMENTS}

\section{The research was conducted under the financial support of the Russian Science Foundation grant (project No. 18-73-10015).}

\section{REFERENCES}

[1] GOLDSTEIN, M. IEEE Computer Society Phoenix Chapter - Internet of Things Innovations \& Megatrends Update. [online]. [viewed 03.08.2020]. Available from: https://www.slideshare.net/markgirc/ieee-computer-society-phoenixchapter-internet-of-things-innovations-megatrends-update-121119.

[2] KHAN, Y., OSTFELD, A.E., LOCHNER, C.M., PIERRE, A., ARIAS, A.C. Monitoring of Vital Signs with Flexible and Wearable Medical Devices. Advanced Materials. [online]. 2016, vol. 28, pp. 4373-4395. Available from: https://doi.org/10.1002/adma.201504366.

[3] MACKUS, A.J.M., SCHNEIDER, J.R., MACISAAC, C., BAKER, J.G., BENT, S.F. Synthesis of Doped, Ternary, and Quaternary Materials by Atomic Layer Deposition: A Review. Chemistry of Materials. [online]. 2019, vol. 31, pp. 1142-1183. Available from: https://doi.org/10.1021/acs.chemmater.8b02878.

[4] NAZAROV, D., EZHOV, I., MITROFANOV, I., LYUTAKOV, O., MAXIMOV, M.Y. The Use of the TMA as Stabilizing Reagent for the Li-O System Obtained by Atomic Layer Deposition. Key Engineering Materials. [online]. 2019, vol. 822, pp. 787-794. Available from: https://doi.org/10.4028/www.scientific.net/KEM.822.787.

[5] MAXIMOV, M., NAZAROV, D., RUMYANTSEV, A., KOSHTYAL, Y., EZHOV, I., MITROFANOV, I., KIM, A., MEDVEDEV, O., POPOVICH, A. Atomic Layer Deposition of Lithium-Nickel-Silicon Oxide Cathode Material for Thin-Film Lithium-Ion Batteries. Energies. [online]. 2020, vol. 13. Available from: https://doi.org/10.3390/en13092345.

[6] TANG, H., JIANG, M.J., ZHANG, Y., LAI, X.X., CUI, C., XIAO, H.Y., JIANG, S.X., REN, E.H., QIN, Q., GUO, R.H. CNTs anchored on defective bimetal oxide NiCoO2-x microspheres for high-performance lithium-ion battery anode. Electrochimica Acta. [online]. 2020, vol. 354. Available from:

https://doi.org/10.1016/i.electacta.2020.136760.

[7] HUANG, Z.D., ZHANG, K., ZHANG, T.T., YANG, X.S., LIU, R.Q., LI, Y., LIN, X.J., FENG, X.M., MA, Y.W., HUANG, W. Hierarchical NiCoO2 mesoporous microspheres as anode for lithium ion batteries with superior rate capability. Energy Storage Materials. [online]. 2016, vol. 3, pp. 36-44. Available from: https://doi.org/10.1016/i.ensm.2016.01.001.

[8] POIZOT, P., LARUELLE, S., GRUGEON, S., TARASCON, J.M. Rationalization of the low-potential reactivity of 3d-metal-based inorganic compounds toward Li. Journal of the Electrochemical Society. [online]. 2002, vol. 149, pp. A1212-A1217. Available from: https://doi.org/10.1149/1.1497981.

[9] PARK, C.M., KIM, J.H., KIM, H., SOHN, H.J. Li-alloy based anode materials for Li secondary batteries. Chemical Society Reviews. [online]. 2010, vol. 39, pp. 3115-3141. Available from: https://doi.org/10.1039/b919877f. 
[10] NAZAROV, D.V., MAXIMOV, M.Y., NOVIKOV, P.A., POPOVICH, A.A., SILIN, A.O., SMIRNOV, V.M., BOBRYSHEVA, N.P., OSMOLOVSKAYA, O.M., OSMOLOVSKY, M.G., RUMYANTSEV, A.M. Atomic layer deposition of tin oxide using tetraethyltin to produce high-capacity Li-ion batteries. Journal of Vacuum Science \& Technology A. [online]. 2017, vol. 35. Available from: https://doi.org/10.1116/1.4972554.

[11] KOSHTYAL, Y., NAZAROV, D., EZHOV, I., MITROFANOV, I., KIM, A., RYMYANTSEV, A., LYUTAKOV, O., POPOVICH, A., MAXIMOV, M. Atomic Layer Deposition of NiO to Produce Active Material for Thin-Film LithiumIon Batteries. Coatings. [online]. 2019, vol. 9. Available from: https://doi.org/10.3390/coatings 9050301.

[12] MITROFANOV, I., EZHOV, I., YURY, K., NAZAROV, D., Kim, A., RUMYANTSEV, A., POPOVICH, A., MAXIMOV, $M$. Synthesis of lithium and cobalt oxides systems by the ald method to obtain lithium cobalt oxide cathode for thin-film libs. In: NANOCON 2019 - 11th International Conference on Nanomaterials - Research \& Application. Brno, Czech Republic: TANGER, 2019, pp. 251-256.

[13] REDDY, M.V., PRITHVI, G., LOH, K.P., CHOWDARI, B.V.R. Li Storage and Impedance Spectroscopy Studies on Co3O4, $\mathrm{CoO}$, and CoN for Li-Ion Batteries. Acs Applied Materials \& Interfaces. [online]. 2014, vol. 6, pp. 680-690. Available from: https://doi.org/10.1021/am4047552.

[14] CAO, K.Z., JIN, T., YANG, L., JIAO, L.F. Recent progress in conversion reaction metal oxide anodes for Li-ion batteries. Materials Chemistry Frontiers. [online]. 2017, vol. 1, pp. 2213-2242. Available from: https://doi.org/1 $\underline{0.1039 / c 7 q m 00175 d}$. 